\title{
Plane of nutrition during the preweaning period but not the grower phase influences the neutrophil activity of Holstein calves
}

\author{
B. S. Obeidat, ${ }^{*}$ C C. J. Cobb, ${ }^{*}$ M. D. Sellers, ${ }^{*}$ A. R. Pepper-Yowell, ${ }^{*}$ T. J. Earleywine, $\ddagger$ and M. A. Ballou ${ }^{* 1}$ \\ *Department of Animal and Food Sciences, Texas Tech University, Lubbock 79409 \\ †Department of Animal Production, Faculty of Agriculture, Jordan University of Science and Technology, Irbid, Jordan \\ łLand O'Lakes, Animal Milk Products Co., Shoreview, MN 55126
}

\section{ABSTRACT}

Two experiments were conducted to determine the influence of plane of nutrition during (1) the pre- and immediate postweaning periods and (2) the grower phase on the performance and leukocyte responses of Holstein calves. In experiment 1, 39 ( $2 \pm 1 \mathrm{~d}$ old $)$ colostrum-fed heifer calves were randomly assigned to 2 planes of nutrition, a low ( $\mathrm{LPN} ; \mathrm{n}=19)$ and a high plane of nutrition (HPN; $n=20)$. Calves in the LPN treatment were offered $418 \mathrm{~g} / \mathrm{d}$ of dry matter $(\mathrm{DM})$ of a $20 \%$ crude protein (CP)/20\% fat milk replacer, whereas calves in the HPN treatment were offered 747 and 1,010 $\mathrm{g} / \mathrm{d}$ of $\mathrm{DM}$ of a $28 \% \mathrm{CP} / 20 \%$ fat milk replacer during wk 1 and wk 2 to 6 , respectively. Calves were offered ad libitum access to a calf starter until the end of the study. Peripheral blood samples were collected on d $3,10,21,45,47,53$, and 91 for many ex vivo leukocyte responses and biochemical analyses. A nutrition $\times$ time interaction was present for average daily gain and feed efficiency (feed:gain ratio). A nutrition $\times$ time interaction existed for plasma glucose concentration. Neutrophil L-selectin expression was greater in calves fed the LPN than HPN on d 3 and 21. The percentage of neutrophils producing an oxidative burst (OB) when cocultured with Escherichia coli tended to be greater and was greater in calves fed the LPN than HPN on d 10 and 21, respectively. In addition, neutrophils from calves fed the LPN had greater OB intensity throughout the neonatal period ( 0 to $21 \mathrm{~d}$ ). However, plasma haptoglobin was not different between the 2 planes of nutrition throughout the study. In experiment 2, 50 heifer calves that were all previously fed a HPN similar to that described for experiment 1 were randomly assigned to 2 planes of nutrition (HPN and LPN) during the grower phase (5 pens/treatment; 5 calves/pen). Calves fed the HPN during the grower phase were fed $4.1 \mathrm{~kg}$ of concentrate DM (pellets; $22.4 \% \mathrm{CP}$, DM

Received February 15, 2013.

Accepted August 10, 2013.

${ }^{1}$ Corresponding author: michael.ballou@ttu.edu basis) per head per day, whereas calves on the LPN during the grower phase were fed $1.6 \mathrm{~kg}$ of $\mathrm{DM}$ of the same concentrate per head per day. All calves were fed alfalfa hay (16.2\% CP; DM basis) ad libitum. Overall, average daily gain was greater in HPN calves than LPN calves. No differences were noticed for concentrations of plasma urea nitrogen, glucose, neutrophil L-selectin expression, percentage of neutrophils producing $\mathrm{OB}$, and plasma haptoglobin concentration between the 2 planes of nutrition. In summary, intake and performance were improved in calves fed the HPN than calves fed the LPN in both experiments. The neutrophil responses of calves fed an LPN were more active during the preweaning period than calves fed an HPN; however, this response was not observed during the immediate postweaning period or the grower phase.

Key words: calf, health, immune, nutrition

\section{INTRODUCTION}

Successful raising of dairy calves can be defined as reaching breeding size with good body conformation, low medication usage, and at a young age. The preweaning and grower periods are critical not only because calves are more susceptible to infectious diseases, but because their overall productive life depends on these periods (Brown et al., 2005; Soberon et al., 2012). In general, the traditional or conventional preweaning feeding program is designed to decrease dependency on fluid milk, stimulate starter intake, and therefore decrease age at weaning. However, interest in feeding high planes of nutrition (HPN) to dairy calves has increased recently. Calves fed HPN during the preweaning period have improved growth performance, feed efficiencies, reach sexual maturity at a younger age, have more mammary parenchymal tissue, and produce more milk as a lactating animal (Blome et al., 2003; Brown et al., 2005; Soberon et al., 2012). The role that plane of nutrition plays on the health of calves is less understood.

A limited amount of research evidence suggests that some leukocyte responses are affected by plane of pre- 
weaning nutrition; however, a clear understanding of the effect and whether it translates into improved health are not known. Nonnecke et al. (2003) found that blood mononuclear leukocytes produced less mitogen-induced IFN- $\gamma$ and more inducible nitric oxide from calves fed an HPN compared with calves fed a low plane of nutrition (LPN). Pollock et al. (1994) also reported that calves fed an HPN had decreased concentrations of antigen-specific IgA and $\operatorname{IgG}_{2}$. In contrast, Foote et al. (2007) did not observe any difference in either the percentages of memory CD4+ and CD8+ T lymphocytes or antigen-induced IFN- $\gamma$ secretion. Ballou (2012) evaluated the effects of breed and planes of preweaning nutrition on various leukocyte responses, including neutrophil oxidative burst (OB) and whole-blood bactericidal capacities. Feeding an HPN, irrespective of breed, increased neutrophil OB at $42 \mathrm{~d}$ of age, immediately before the weaning process was initiated. No differences were observed in any of the other immune measurements, an in vivo acute-phase response to a lipopolysaccharide, whole-blood bactericidal capacity, or stimulated peripheral blood mononuclear cell cytokine production, due to plane of nutrition during the preweaning period among either Jersey or Holstein calves in that study. However, Jersey calves previously fed the LPN had decreased neutrophil OB and wholeblood bactericidal capacity during the postweaning period. Therefore, despite the paucity of data, plane of preweaning nutrition influences leukocyte responses of calves with greater innate leukocyte responses, but reduced adaptive immune measures.

Weaning is potentially stressful to calves because there is a dramatic or sudden change in their feed management and nutrition. Stress suppresses many leukocyte responses and increases the relative risk for developing an infectious disease. Hulbert et al. (2011) reported that many neutrophil responses, including expression of surface adhesion molecules and $\mathrm{OB}$, were suppressed at weaning in calves fed an LPN. Conceivably, calves fed an HPN during the preweaning period may be more stressed and have greater suppression in neutrophil responses during weaning because the change in nutrition is more drastic. In fact, Holstein calves fed an HPN have reduced calf starter intake and, if weaned too abruptly, they have a lag in postweaning performance (Ballou et al., 2013).

During the grower phase, calves are often commingled and experience an increased incidence of infectious diseases, especially respiratory disease (NAHMS, 2007; Hulbert and Ballou, 2012). No data exist from investigation of the role of plane of nutrition during the grower phase on leukocyte responses of growing heifers; however, data from young beef cattle entering a feedlot suggested that cattle fed higher concentrate diets had an increased incidence of respiratory disease and more aggressive acute-phase responses when exposed to pathogens (Lofgreen et al., 1975; Rivera et al., 2005). Schwertner et al. (2011) also reported that recently weaned beef steers fed a $70 \%$ concentrate diet ad libitum had peripheral blood mononuclear cells that produced more tumor necrosis factor- $\alpha$ (TNF- $\alpha)$ than from steers fed a $30 \%$ concentrate diet ad libitum. In addition, the steers fed the $70 \%$ concentrate diet had a greater acute-phase response following an intranasal challenge with infectious bovine rhinotracheitis virus. Therefore, growing heifers fed a high percentage of concentrates in the ration may have an elevated acutephase response and increased incidence of clinical diseases when commingled.

The first hypothesis was that feeding an HPN to Holstein calves during the preweaning period would increase the neutrophil OB. The second hypothesis was that weaning would be stressful and suppress leukocyte responses and the effect would be greater among Holstein calves fed an HPN during the preweaning period. The third hypothesis was that Holstein calves fed an HPN during the preweaning period that continued to be fed an HPN during the grower phase would have greater production of TNF- $\alpha$ and plasma haptoglobin concentrations. To test these hypotheses, 2 experiments were conducted that evaluated leukocyte responses of Holstein calves: (1) calves were fed either an HPN or LPN during the pre- and immediate postweaning periods and (2) calves that were previously fed an HPN during the preweaning period were either continued on an HPN or switched to an LPN during the grower phase.

\section{MATERIALS AND METHODS}

The Texas Tech University Animal Care and Use Committee reviewed and approved all procedures used in the 2 experiments, which were conducted at the Hilmar Cheese and Agri-Plastics Calf Research Facility at Texas Tech University (New Deal).

\section{Experiment 1}

Calves, Diets, and Housing. Thirty-nine Holstein heifer calves ( $2 \pm 1 \mathrm{~d}$ old; $37.6 \pm 4.74 \mathrm{~kg}$ of initial BW) were randomly assigned to 1 of 2 planes of nutrition; an LPN ( $\mathrm{n}=19)$ or an HPN $(\mathrm{n}=20)$. At enrollment, a peripheral blood sample was drawn (6-mL no additive Vacutainer, Becton Dickinson, Franklin Lakes, NJ) and total serum proteins were recorded using a hand-held refractometer (Atago USA Inc., Bellevue, WA). No difference in the serum protein was observed between treatments and the average was $5.9 \pm 0.50 \mathrm{~g} /$ 
dL. Calves in the LPN group were offered $418 \mathrm{~g} / \mathrm{d}$ of DM of a $20 \% \mathrm{CP} / 20 \%$ fat milk replacer (MR; Herd Maker, Land O'Lakes Animal Milk Products Co., Shoreview, MN; Table 1), whereas calves in the HPN group were offered 747 and $1,010 \mathrm{~g} / \mathrm{d} \mathrm{DM}$ of a $28 \% \mathrm{CP} / 20 \%$ fat MR (Cow's Match; Land O'Lakes Animal Milk Products Co.) during wk 1 and wk 2 to 6 , respectively. Milk replacer was mixed with warm water $\left(43-48^{\circ} \mathrm{C}\right)$ to dissolve the powder and then mixed with cold water to reach the required volume at approximately $38^{\circ} \mathrm{C}$. The MR was fed at 11.0 and $16.4 \%$ DM for LPN and HPN, respectively. Milk replacer was offered to the calves using plastic bottles with a nipple.

Throughout the study, calves were individually housed in commercial polyethylene calf hutches $(2.13$ $\times 1.09 \mathrm{~m}$; Agri-Plastics Inc., Tonawanda, NY) with an attached outside pen $(1.83 \times 1.09 \mathrm{~m})$, and fed their respective MR twice daily at 0730 and $1630 \mathrm{~h}$. The study was conducted from June to August 2011. No bedding material was provided in the calf hutches over the course of the experiment and pens were soil-surfaced.
After the first week, calves were offered their respective calf starter (Table 1) ad libitum until the end of the study at $91 \mathrm{~d}$. Before the morning feeding, the quantity of calf starter was recorded and the amount offered was adjusted daily for approximately a $10 \%$ refusal. The calves were offered free access to water throughout the experiment. No hay was offered during this experiment. A gradual weaning process was started at d 45 after initiation of the treatments by removing the p.m. milk bottle feeding and continuing with the a.m. feeding. The a.m. MR feeding was removed when calves were past d 53 and consuming $800 \mathrm{~g}$ of calf starter DM per day for 2 consecutive days. All calves fed the LPN and 18 of the $20 \mathrm{HPN}$ calves were consuming greater than $800 \mathrm{~g}$ of calf starter DM at d 53. Calves were vaccinated on d 35 and given a booster on d 56 with Vista 5 SQ and Vision 7 with SPUR (Merck Animal Health, Summit, NJ).

Fecal scores were recorded according to the guidelines outlined by Larson et al. (1977). Scores were, $1=$ firm, well-formed (not hard); 2 = soft, pudding-like; 3

Table 1. The formulated nutrient content of the milk replacer and calf starter fed to Holstein calves (experiment 1)

\begin{tabular}{|c|c|c|c|c|}
\hline \multirow[b]{2}{*}{ Nutrient } & \multicolumn{2}{|c|}{ Milk replacer ${ }^{1}$} & \multicolumn{2}{|c|}{ Calf starter ${ }^{2}$} \\
\hline & LPN & $\mathrm{HPN}$ & $\mathrm{LPN}$ & $\mathrm{HPN}$ \\
\hline $\mathrm{CP}$ (minimum), \% & 20.0 & 28.0 & 18.0 & 20.0 \\
\hline Ether extract (minimum), \% & 20.0 & 20.0 & 2.2 & 2.2 \\
\hline Crude fiber (maximum), \% & 0.15 & 0.15 & 12.5 & 16.0 \\
\hline Acid detergent fiber (maximum), $\%$ & - & - & 14.5 & 18.0 \\
\hline $\mathrm{ME},{ }^{3} \mathrm{Mcal} / \mathrm{kg}$ & 4.78 & 4.91 & 2.55 & 2.66 \\
\hline $\mathrm{Ca}$ (minimum), \% & 0.75 & 0.75 & 0.80 & 0.80 \\
\hline $\mathrm{Ca}$ (maximum), \% & 1.25 & 1.25 & 1.20 & 1.20 \\
\hline $\mathrm{P}$ (minimum) $\%$ & 0.70 & 0.70 & 0.45 & 0.50 \\
\hline $\mathrm{Se}(\operatorname{minimum}), \mathrm{mg} / \mathrm{kg}$ & - & - & 0.30 & 0.30 \\
\hline Vitamin A (minimum), KIU $/ \mathrm{kg}$ & 44 & 44 & 6,380 & 7,700 \\
\hline Vitamin $\mathrm{D}_{3}$ (minimum), KIU/kg & 11 & 11 & - & - \\
\hline Vitamin E (minimum), IU/kg & 220 & 220 & - & - \\
\hline
\end{tabular}

${ }^{1}$ Two commercial milk replacers were fed. LPN $=$ low plane of nutrition was a commercial milk replacer (Herd Maker; Land O'Lakes Animal Milk Products Co., Shoreview, MN) that was supplemented with dicalcium phosphate, calcium carbonate, vitamin $\mathrm{A}$ acetate, vitamin $\mathrm{D}_{3}$, vitamin $\mathrm{E}$, thiamine mononitrate, pyridoxine hydrochloride, folic acid, vitamin $\mathrm{B}_{12}$, choline chloride, calcium silicate, manganese sulfate, zinc sulfate, ferrous sulfate, copper sulfate, cobalt sulfate, ethylenediamine dihydroiodide, and selenium yeast. HPN = high plane of nutrition was a commercial milk replacer (Cow's Match; Land O'Lakes Animal Milk Products Co.) that was supplemented with a dried Saccharomyces cerevisiae fermentation extract and trace minerals and vitamins at the same concentrations as the LPN milk replacer, but used mostly organic sources, including zinc methionine, manganese methionine, copper lysine, iron amino acid complex, ethylenediamine dihydroiodide, and selenium yeast.

${ }^{2}$ Two commercial calf starters with monensin were fed using similar macro-ingredients, which included grain products, processed grain by-products, plant protein products, molasses, and roughage products. The LPN calf starter (Calf Startena; Purina Mills LLC, Gray Summit, MO) was formulated with trace minerals and vitamins similar to that found in the LPN milk replacer. The HPN calf starter (Cornerstone Ampli-Calf; Purina Mills LLC) was formulated with a proprietary blend of a yeast extract, fructooligosaccharide, anise oil, garlic oil, cassia, ethyl vanillin, and propylene glycol. The HPN calf starter also was formulated with a trace mineral and vitamins at the same concentrations as the LPN calf starter but used mostly organic sources, including zinc amino acid complex, manganese amino acid complex, copper amino acid complex, cobalt glucoheptonate, and cobalt proteinate.

${ }^{3}$ Calculated according to NRC (2001). 
$=$ runny, similar in consistency to pancake batter; and $4=$ liquid, splatters, similar in consistency to pulpy orange juice. All fecal scores were recorded by observing fecal matter on the ground of the pen and on the tail and hind quarters of the calves. Fecal score data were collected by 1 independent trained observer and averaged across 3 consecutive days before statistical analysis.

Animal Measurements and Metabolites and Immune Measures. Before the morning feeding, calf BW was measured on d 3, 10, 21, 53, and 91 to evaluate $\mathrm{ADG}$, feed:gain ratio, and other performance efficiencies. All performance data were calculated and reported for the following time periods: 0 to $21 \mathrm{~d}$ (neonatal period), 0 to $53 \mathrm{~d}$ (preweaning period), 53 to $91 \mathrm{~d}$ (immediate postweaning period), and 0 to $91 \mathrm{~d}$ (overall period). For each calf, bone lengths were measured, hoof to scapula and scapula to the pins, to the nearest $0.25 \mathrm{~cm}$ using a tape measure at d 0,21, 53, and 91 . All data are reported as day relative to initiation of treatments.

Peripheral blood samples $(13 \mathrm{~mL})$ were collected before feeding on $\mathrm{d} 3,10,21,45,47,53$, and 91 from the jugular vein and analyzed for blood metabolite concentrations and various leukocyte responses following the procedures outlined by Sellers et al. (2013). Plasma was analyzed for glucose, urea nitrogen, and haptoglobin concentrations. Plasma glucose and urea nitrogen concentrations were analyzed using commercially available enzymatic reagents (Stanbio Laboratory, Boerne, TX). The intra- and interassay coefficients of variation were 5.4 and $5.1 \%$ for glucose and 6.4 and $6.8 \%$ for urea nitrogen, respectively. Plasma haptoglobin concentration was measured according to the procedures described by Hulbert et al. (2011). The intra- and interassay CV for plasma haptoglobin were 1.4 and $3.4 \%$, respectively. All colorimetric data were measured on a SpectraMax 340PC (Molecular Devices LLC, Sunnyvale, CA).

Tumor necrosis factor- $\alpha$ was measured ex vivo using the whole-blood stimulation protocol of Ballou et al. (2009). In brief, blood was diluted 1:4 in RPMI medium supplemented with 1\% antibiotic-antimycotic (Invitrogen Life Technologies, Grand Island, NY). The culture was then stimulated with a commercially available LPS (Escherichia coli 0111:B4; Sigma, St. Louis, MO) at a final concentration of $1 \mu \mathrm{g} / \mathrm{mL}$. Cell suspensions were incubated for $24 \mathrm{~h}$ at $38^{\circ} \mathrm{C}$ in a humidified $5 \% \mathrm{CO}_{2}$ incubator. Following incubation, the cell suspensions were centrifuged for $15 \mathrm{~min}$ at $1,200 \times g$, supernatant was removed and stored at $-40^{\circ} \mathrm{C}$ until analysis for concentrations of TNF- $\alpha$ by a commercially available ELISA kit (R\&D Systems Inc., Minneapolis, MN). A 7-step serially diluted recombinant bovine TNF- $\alpha$ standard curve was used. The intra- and interassay coef- ficients of variation for the ELISA were 3.9 and $4.4 \%$, respectively.

To evaluate neutrophil L-selectin expression, $200 \mu \mathrm{L}$ of whole blood from each sample was incubated with anti-bovine CD62L (monoclonal antibody IgG1-isotype made in mouse; VMRD Inc., Pullman, WA) at a final dilution of $5 \mu \mathrm{g} / \mathrm{mL}$ for $1 \mathrm{~h}$ in an ice bath. Erythrocytes were hypotonically lysed and then rinsed twice with $1 \times$ PBS. The leukocyte pellet was resuspended in fluorescein-labeled secondary antibody at a 1:400 dilution $\left[\mathrm{F}\left(\mathrm{ab}^{\prime}\right) 2\right.$ anti-mouse IgG:FITC; AbD Serotec Inc., Raleigh, $\mathrm{NC}]$ and incubated on ice for an additional $1 \mathrm{~h}$. Cells that only received secondary antibody served as negative controls. Samples were then washed twice using $1 \times$ PBS and analyzed by single-color flow cytometry. Using the flow cytometer analysis software, neutrophils were gated based on the scatterplot of electric volume $\times$ side scatter. Finally, the total FL-3 (fluorescence channel 3) geometric mean fluorescence intensity (GMFI) of cells determined to be neutrophils was reported.

The capacity of neutrophils to produce an OB when cocultured with $E$. coli was evaluated using procedures of Hulbert et al. (2011). Two hundred microliters of whole blood for each sample was incubated in an ice bath for 15 min to quash cellular activity. Forty microliters each of a $100 \mu M$ working concentration of dihydrorhodamine (DHR; Invitrogen Life Technologies) and heat-killed $E$. coli at $1 \times 10^{6}$ cells $/ \mathrm{mL}$ were added to every sample, vortexed thoroughly, and then placed in a $38.5^{\circ} \mathrm{C}$ water bath and incubated for $10 \mathrm{~min}$. After completion of incubation, the samples were immediately placed in an ice bath for 5 min to stop the reaction at a constant rate. Erythrocytes were hypotonically lysed and washed with $1 \times$ PBS. The leukocytes were then analyzed using a Cell Lab Quanta SC dual-color flow cytometer (Beckman Coulter Inc., Fullerton, CA). Using flow cytometry analysis software (Quanta SC MPL; Beckman Coulter Inc.), neutrophils were gated on the scatterplot of electric volume $\times$ side scatter. The percentage of cells determined to be neutrophils that were positive for OB was gated as neutrophils that had greater fluorescence intensity than neutrophils from control cultures that were incubated without $E$. coli. Data are reported as both the percentage of neutrophils positive for OB as well as the FL-3 GMFI of the positive population.

Statistical Analyses. Data were analyzed by ANOVA for a completely randomized design with repeated measures using PROC MIXED of SAS (version 9.2; SAS Institute Inc., Cary, NC). Model effects included nutrition, time, and the nutrition $\times$ time interaction, where time was a repeated effect and calf served as the experimental unit. The linear mixed model was ana- 
lyzed with all available covariance structures for calf nested within treatment. The appropriate covariance structure of the data was chosen for each variable from the structures of compound symmetric, autoregressive (1), and unstructured using the smallest Bayesian information criterion. A Kenward-Roger correction was applied to the denominator degrees of freedom to obtain the appropriate standard errors and $F$-statistics for each model. Normality of the residuals was confirmed by evaluating the Shapiro-Wilk statistic and normal probability plots using PROC UNIVARIATE of SAS (version 9.2). Means were subsequently separated using the sliced time effects for plane of nutrition $\times$ time interaction and the PDIFF function associated with generation of least squares means $( \pm \mathrm{SEM})$. Differences were considered significant at $P \leq 0.05$.

\section{Experiment 2}

Fifty heifer calves previously fed an HPN similar to that described in experiment 1 were randomly assigned to either an LPN or HPN grower-phase diet to evaluate the influence of plane of nutrition during the grower phase on ADG and leukocyte responses. This study was not designed to test for any interaction between preweaning and grower-phase plane of nutrition. Calves that were previously fed an HPN during the preweaning period were used in this experiment because an additional objective was to describe the growth and feed efficiencies of those growing heifers when either transitioned to an LPN or maintained on a high-concentrate HPN grower ration. Calves fed the HPN ( 5 pens; 5 calves/ pen) during the grower phase were fed $4.1 \mathrm{~kg}$ of DM of concentrate pellets (Ampli-Calf; Purina Mills LLC, Gray Summit, MO) per head per day, whereas calves on the LPN diet during the grower phase ( 5 pens; 5 calves/ pen) were fed $1.6 \mathrm{~kg}$ of $\mathrm{DM}$ of the same concentrate per head per day. All calves were offered alfalfa hay ad libitum and had free access to water. Intakes of the concentrate and alfalfa hay were each recorded daily. The hay and the concentrate were analyzed according to AOAC International (1995) procedures. The chemical composition for the concentrate was $97.3,22.4$, and $22.5 \%$ DM, CP, and starch, respectively, whereas the hay was $91.5,16.2,44.1$, and $30.0 \% \mathrm{DM}, \mathrm{CP}, \mathrm{NDF}$, and ADF, respectively. The concentrate pellet was formulated with similar ingredients, micronutrients, and feed additives as the HPN calf starter (Table 1). Calves were group housed ( 5 calves/pen) in commercial polyethylene calf hutches $(2.69 \times 2.26 \mathrm{~m}$; Agri-Plastics Inc. $)$ with an attached outside pen $(4.88 \times 3.05 \mathrm{~m})$. In each pen, calves were fed their respective diets during the grower phase during d 91 to 162 . To measure ADG, calf BW was measured on d 91, 113, 133, and 162. On the same days that calves were weighed, peripheral blood samples were collected from the jugular vein and analyzed for blood metabolite concentrations and leukocyte responses as described in experiment 1. For each calf, bone lengths were measured, hoof to scapula and scapula to the pins, to the nearest $0.25 \mathrm{~cm}$ using a tape measure at d 91 , 113,133 , and 162.

Data were analyzed by ANOVA with repeated measures using the PROC MIXED of SAS (version 9.2). All data were analyzed with pen as the experimental unit. The model included the effects of nutrition, time, and the nutrition $\times$ time interaction, where time was the repeated effect, with the subject equal to pen nested within treatment. For the blood metabolites and leukocyte response, data collected on d 91 were used as a covariate. The linear mixed models were analyzed with all available covariance structures and the most appropriate selected based on the lowest Bayesian information criterion. A Kenward-Roger correction was applied to the denominator degrees of freedom to obtain the appropriate standard errors and $F$-statistics for each model. Normality of the residuals was confirmed by evaluating the Shapiro-Wilk statistic and normal probability plots using the PROC UNIVARIATE of SAS (version 9.2). Means were subsequently separated using the sliced time effects for plane of nutrition $\times$ time interaction and the PDIFF function associated with generation of least squares means $( \pm$ SEM). Differences were considered significant at $P \leq 0.05$.

\section{RESULTS}

\section{Experiment 1}

Intakes, Fecal Scores, and Growth Performance. Intake of MR was greater in HPN calves compared with LPN calves during the neonatal and overall preweaning periods (d 0 to 45; Table 2). Starter intake was greater for LPN than HPN calves during the preweaning and overall periods, but was not different $(P \geq$ 0.54 ) during the neonatal and immediate postweaning periods. Over the course of the study, no nutrition or nutrition $\times$ time effects $(P \geq 0.19)$ were observed for fecal scores.

A nutrition $\times$ time interaction $(P<0.05)$ was detected for ADG between diets (Table 2). The ADG was greater $(P<0.05)$ for HPN calves than LPN calves during the neonatal, preweaning, and overall periods, and ADG tended to be greater $(P=0.06)$ for HPN than LPN calves during the immediate postweaning period. A nutrition $\times$ time interaction $(P<0.05)$ was observed in feed efficiency (feed:gain ratio) between diets. Feed efficiency was higher in HPN calves than LPN calves during the neonatal, preweaning, and overall periods, 
Table 2. Influence of plane of nutrition on milk replacer intake, starter intake, and growth performance of Holstein calves (experiment 1)

\begin{tabular}{|c|c|c|c|c|}
\hline \multirow[b]{2}{*}{ Item } & \multicolumn{2}{|c|}{ Nutrition $^{1}$} & \multirow[b]{2}{*}{ SEM } & \multirow[b]{2}{*}{$P$-value } \\
\hline & LPN & $\mathrm{HPN}$ & & \\
\hline \multicolumn{5}{|l|}{ Milk replacer, ${ }^{2} \mathrm{~kg} / \mathrm{d}$} \\
\hline d 0 to 21 & 0.40 & 0.80 & 0.008 & $<0.05$ \\
\hline d 0 to 45 & 0.41 & 0.90 & 0.008 & $<0.05$ \\
\hline \multicolumn{5}{|l|}{ Starter, kg/d } \\
\hline d 0 to 21 (neonatal period) & 0.08 & 0.04 & 0.051 & 0.54 \\
\hline d 0 to 53 (preweaning period) & 0.48 & 0.18 & 0.051 & $<0.05$ \\
\hline d 53 to 91 (postweaning) & 2.31 & 2.29 & 0.051 & 0.69 \\
\hline d 0 to 91 (overall) & 1.23 & 1.08 & 0.051 & $<0.05$ \\
\hline \multicolumn{5}{|l|}{ Average daily gain, $\mathrm{kg} / \mathrm{d}$} \\
\hline d 0 to 21 (neonatal period) & 0.22 & 0.63 & 0.028 & $<0.05$ \\
\hline d 0 to 53 (preweaning period) & 0.39 & 0.61 & 0.028 & $<0.05$ \\
\hline d 53 to 91 (postweaning) & 0.83 & 0.90 & 0.028 & 0.06 \\
\hline d 0 to 91 (overall) & 0.56 & 0.73 & 0.028 & $<0.05$ \\
\hline \multicolumn{5}{|l|}{ Feed:gain ratio } \\
\hline d 0 to 21 (neonatal period) & 2.64 & 1.28 & 0.124 & $<0.05$ \\
\hline d 0 to 53 (preweaning period) & 2.15 & 1.54 & 0.126 & $<0.05$ \\
\hline d 53 to 91 (postweaning) & 2.87 & 2.60 & 0.126 & 0.13 \\
\hline d 0 to 91 (overall) & 2.58 & 2.09 & 0.124 & $<0.05$ \\
\hline
\end{tabular}

${ }^{1} \mathrm{LPN}=$ low plane of nutrition $(\mathrm{n}=19) ; \mathrm{HPN}=$ high plane of nutrition $(\mathrm{n}=20)$.

${ }^{2}$ The data of milk replacer intake were only reported until $45 \mathrm{~d}$ of age. This is because weaning was initiated at $\mathrm{d} 45$ by removing the p.m. feeding, and calves were completely weaned when they were consuming $800 \mathrm{~g}$ of calf starter DM after $53 \mathrm{~d}$.

whereas efficiency was similar $(P=0.13)$ during the immediate postweaning period. Overall, HPN calves had longer bone structure $(P<0.05)$ than LPN calves. Mean bone length from hoof to scapula was $93.6 \pm$ 0.70 and $90.7 \pm 0.72 \mathrm{~cm}$ for the HPN and LPN calves, respectively. Also, bone length from the scapula to the pins was $69.8 \pm 0.57$ and $66.7 \pm 0.58 \mathrm{~cm}$ for the HPN and LPN calves, respectively.

A nutrition $\times$ time interaction $(P<0.05)$ was detected for the $\mathrm{CP}$ intake $(\mathrm{kg} / \mathrm{d})$ between diets, indicating that CP intake was greater in HPN calves than LPN calves during neonatal, preweaning, and overall periods, whereas during the immediate postweaning period, $\mathrm{CP}$ intake was similar $(P=0.32$; Table 3$)$. No nutrition $\times$ time interaction $(P=0.95)$ was observed for $\mathrm{CP}$ intake per kilogram of BW gain. However, a nutrition effect was detected for CP intake per kilogram of BW gain, being greater $(P<0.05)$ in LPN calves than HPN calves. A nutrition $\times$ time interaction $(P<0.05)$ indicated that $\mathrm{CP}$ intake per $\mathrm{kg} \mathrm{BW}^{0.75}$ was greater in HPN calves compared with LPN calves during the neonatal, preweaning, and overall periods; whereas $\mathrm{CP}$ intake per $\mathrm{kg} \mathrm{BW}^{0.75}$ was greater in LPN calves than HPN calves during the immediate postweaning period.

A nutrition $\times$ time interaction $(P<0.05)$ was observed for ME intake (Mcal/d) between diets (Table 3). Metabolizable energy intake was greater in HPN calves compared with LPN calves during the neonatal, preweaning, and overall periods, whereas ME intake was not different $(P=0.31)$ during the immediate postweaning period. A nutrition $\times$ time interaction $(P$ $<0.05)$ indicated that the intake of ME per kilogram of BW gain was greater in LPN calves than HPN calves during the neonatal period, whereas ME intake per kilogram of BW gain was similar $(P \geq 0.13)$ between the diets during the other periods. A nutrition $\times$ time interaction $(P<0.05)$ was observed for ME intake per kilogram of $\mathrm{BW}^{0.75}$. Intake of ME per kilogram of $\mathrm{BW}^{0.75}$ was greater in HPN calves compared with LPN calves during the neonatal, preweaning, and overall periods, whereas ME intake per kilogram of $\mathrm{BW}^{0.75}$ was greater in LPN calves than HPN calves during the immediate postweaning period.

Blood Metabolites and Leukocyte Responses. A nutrition $\times$ time interaction $(P<0.05)$ was detected for plasma urea nitrogen concentration (Figure 1a). Plasma urea nitrogen concentration was greater for HPN calves than LPN calves on d 3 only. Plasma glucose concentration exhibited a nutrition $\times$ time interaction $(P<0.05)$ among groups (Figure $1 b)$. Plasma glucose concentration was higher in calves fed HPN than in calves fed LPN on d 3,10,21, and 45, whereas no differences were detected during the remainder of the study.

A nutrition $\times$ time interaction $(P<0.05)$ was observed for the secretion of TNF- $\alpha$ when whole blood was cocultured with LPS (Figure 2). The level of TNF- $\alpha$ production was greater for LPN than HPN calves on d 3 only. A nutrition $\times$ time interaction $(P<0.05)$ was observed for the expression of L-selectin protein on the 
Table 3. Influence of plane of nutrition on CP and ME intakes of Holstein calves (experiment 1)

\begin{tabular}{|c|c|c|c|c|}
\hline \multirow[b]{2}{*}{ Item } & \multicolumn{2}{|c|}{ Nutrition $^{1}$} & \multirow[b]{2}{*}{ SEM } & \multirow[b]{2}{*}{$P$-value } \\
\hline & $\mathrm{LPN}$ & $\mathrm{HPN}$ & & \\
\hline \multicolumn{5}{|l|}{$\mathrm{CP}, \mathrm{kg} / \mathrm{d}$} \\
\hline d 0 to 21 (neonatal period) & 0.10 & 0.22 & 0.011 & $<0.05$ \\
\hline d 0 to 53 (preweaning period) & 0.17 & 0.25 & 0.011 & $<0.05$ \\
\hline d 53 to 91 (postweaning) & 0.49 & 0.50 & 0.011 & 0.32 \\
\hline d 0 to 91 (overall) & 0.32 & 0.36 & 0.011 & $<0.05$ \\
\hline \multicolumn{5}{|l|}{$\mathrm{CP} / \mathrm{kg}$ of $\mathrm{BW}$ gain, $\mathrm{kg}$} \\
\hline d 0 to 21 (neonatal period) & 0.46 & 0.41 & 0.021 & 0.13 \\
\hline d 0 to 53 (preweaning period) & 0.49 & 0.42 & 0.021 & 0.32 \\
\hline d 53 to 91 (postweaning) & 0.62 & 0.59 & 0.022 & 0.32 \\
\hline d 0 to 91 (overall) & 0.54 & 0.50 & 0.021 & 0.18 \\
\hline \multicolumn{5}{|l|}{$\mathrm{CP} / \mathrm{kg}$ of $\mathrm{BW}^{0.75}, \mathrm{~g}$} \\
\hline d 0 to 21 (neonatal period) & 6.40 & 12.81 & 0.349 & $<0.05$ \\
\hline d 0 to 53 (preweaning period) & 9.64 & 12.39 & 0.349 & $<0.05$ \\
\hline d 53 to 91 (postweaning) & 19.98 & 17.76 & 0.353 & $<0.05$ \\
\hline d 0 to 91 (overall) & 13.62 & 14.67 & 0.353 & $<0.05$ \\
\hline \multicolumn{5}{|l|}{$\mathrm{ME}, \mathrm{Mcal} / \mathrm{d}$} \\
\hline d 0 to 21 (neonatal period) & 2.14 & 3.79 & 0.134 & $<0.05$ \\
\hline d 0 to 53 (preweaning period) & 2.97 & 4.12 & 0.132 & $<0.05$ \\
\hline d 53 to 91 (postweaning) & 5.90 & 6.09 & 0.133 & 0.31 \\
\hline d 0 to 91 (overall) & 4.16 & 5.01 & 0.134 & $<0.05$ \\
\hline \multicolumn{5}{|l|}{$\mathrm{ME} / \mathrm{kg}$ of BW gain, Mcal } \\
\hline d 0 to 21 (neonatal period) & 10.26 & 7.03 & 0.397 & $<0.05$ \\
\hline d 0 to 53 (preweaning period) & 7.72 & 6.98 & 0.343 & 0.13 \\
\hline d 53 to 91 (postweaning) & 7.54 & 7.18 & 0.357 & 0.48 \\
\hline d 0 to 91 (overall) & 7.44 & 6.94 & 0.348 & 0.31 \\
\hline \multicolumn{5}{|l|}{$\mathrm{ME} / \mathrm{kg}$ of $\mathrm{BW}^{0.75}, \mathrm{Mcal}$} \\
\hline d 0 to 21 (neonatal period) & 0.14 & 0.22 & 0.005 & $<0.05$ \\
\hline d 0 to 53 (preweaning period) & 0.17 & 0.21 & 0.005 & $<0.05$ \\
\hline d 53 to 91 (postweaning) & 0.24 & 0.21 & 0.005 & $<0.05$ \\
\hline d 0 to 91 (overall) & 0.19 & 0.21 & 0.005 & $<0.05$ \\
\hline
\end{tabular}

${ }^{1} \mathrm{LPN}=$ low plane of nutrition $(\mathrm{n}=19) ; \mathrm{HPN}=$ high plane of nutrition $(\mathrm{n}=20)$.

surface of neutrophils between groups, indicating that neutrophil L-selectin concentration was greater $(P<$ $0.05)$ in LPN calves than in HPN calves on $\mathrm{d} 3$ and 21 and tended to be greater $(P=0.06)$ in LPN calves compared with HPN calves on d 45 (Figure 3). Furthermore, a nutrition $\times$ time interaction $(P<0.05)$ was detected for the percentage of neutrophils producing an OB when cocultured with an E. coli (Figure 4a). The percentage of neutrophil producing $\mathrm{OB}$ was greater in LPN than in HPN calves on d 21 and tended to be greater $(P=0.06)$ on $\mathrm{d} 10$. Similarly, the neutrophil OB intensity (GMFI) exhibited a nutrition $\times$ time interaction $(P<0.05)$ and $\mathrm{OB}$ intensity was greater for LPN than HPN calves on d 3, 10, and 21 (Figure 4b). Over the course of the study, no nutrition or nutrition $\times$ time effects $(P>0.05)$ were observed for plasma concentration of the acute-phase protein haptoglobin. Mean plasma concentrations of haptoglobin were $1.1 \pm$ 0.07 and $1.2 \pm 0.10$ optical densities for LPN and HPN diet, respectively.

\section{Experiment 2}

No differences $(P=0.19)$ were observed for the DMI between the diets (Table 4). However, intakes of CP and ME were greater $(P<0.05)$ in calves fed an HPN than in calves fed an LPN, but when expressed per kilogram of BW gain, no differences were detected in either $\mathrm{CP}$ or $\mathrm{ME}$ intakes $(P \geq 0.61)$. A nutrition $\times$ time interaction $(P<0.05)$ was noticed for ME intake per $\mathrm{kg}$ of $\mathrm{BW}^{0.75}$. Calves fed an HPN consumed more ME per kilogram of $\mathrm{BW}^{0.75}$ than calves fed an LPN during the 91- to $113-d, 113-$ to $134-d$, and 134- to 162-d periods.

Crude protein intake per kilogram of $\mathrm{BW}^{0.75}$ tended $(P=0.07)$ to be greater for HPN calves than LPN calves. A nutrition $\times$ time interaction $(P<0.05)$ was detected for ADG between the diets (Table 4). Average daily gain was greater $(P<0.05)$ in HPN calves than LPN calves during the 91- to 113-d, 113- to 134-d, and 91- to 162-d periods, whereas the 134- to 162-d period was not affected by plane of nutrition. No difference $(P>0.05)$ was observed for the bone lengths of calves from the scapula to the pins $(90.1 \pm 1.21$ and $89.3 \pm 1.24 \mathrm{~cm}$ ) for the HPN and LPN calves, respectively. However, calves fed the HPN diet tended $(P=0.08)$ to have greater bone length from the hoof to the scapula than calves fed the LPN diet. Mean bone lengths were $111.2 \pm 0.70$ and $109.4 \pm 0.72 \mathrm{~cm}$ for the HPN and LPN calves, respectively. No differences $(P \geq 0.24)$ were noticed for concentrations of plasma 
a)

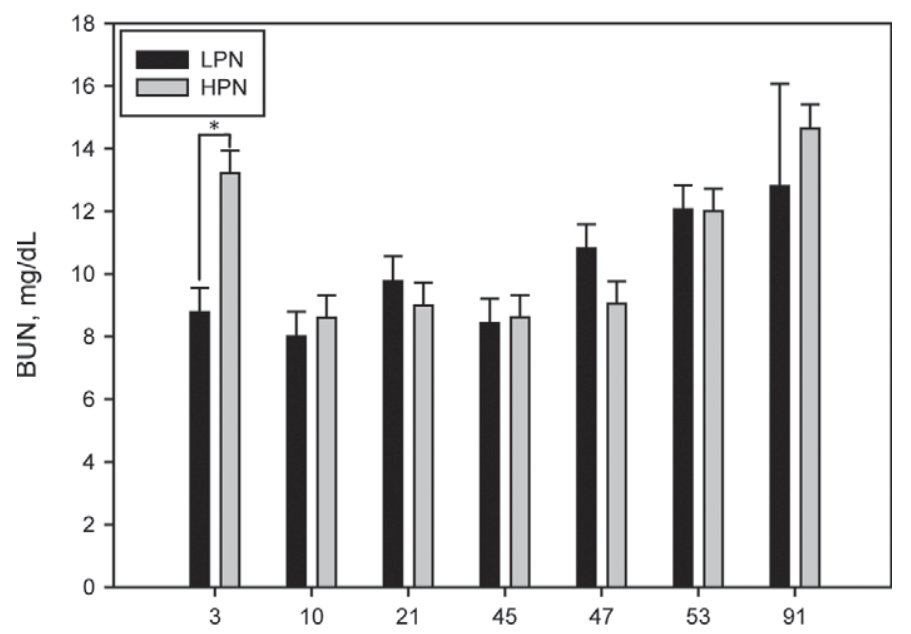

b)

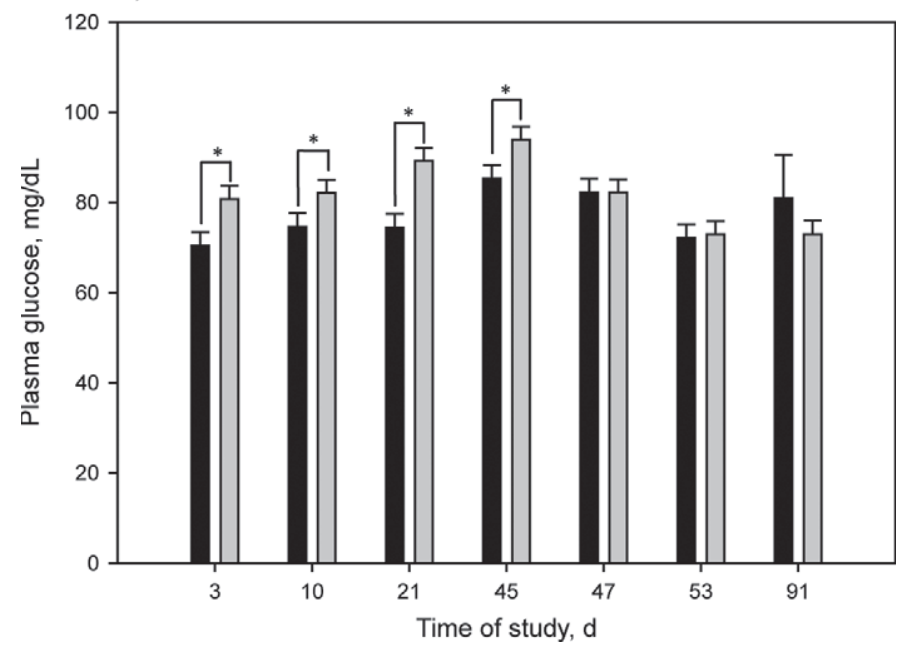

Figure 1. (a) Effects of plane of nutrition on plasma urea nitrogen concentration on d 3, 10, 21 (neonatal period), 45, 47, 53 (weaning period), and 91 (immediately postweaning). Nutrition $\times$ time: $P<$ 0.05 ; sliced effects: ${ }^{*} P<0.05$. Error bars represent SEM (experiment 1). (b) Effects of plane of nutrition on glucose on d 3, 10, 21 (neonatal period), 45, 47, 53 (weaning period), and 91 (immediately postweaning). Nutrition $\times$ time: $P<0.05$; sliced effects: ${ }^{*} P<0.05$. Error bars represent SEM (experiment 1 ). LPN = low plane of nutrition; HPN = high plane of nutrition.

urea nitrogen, glucose, L-selectin protein expression on neutrophils, percentage of neutrophil producing OB, TNF- $\alpha$ production, or plasma haptoglobin concentrations (Table 5).

\section{DISCUSSION}

Calves are extremely susceptible to infectious disease early in life and preventing deaths from infectious disease is critical for dairy farm sustainability and profitability. Therefore, 2 experiments were conducted to

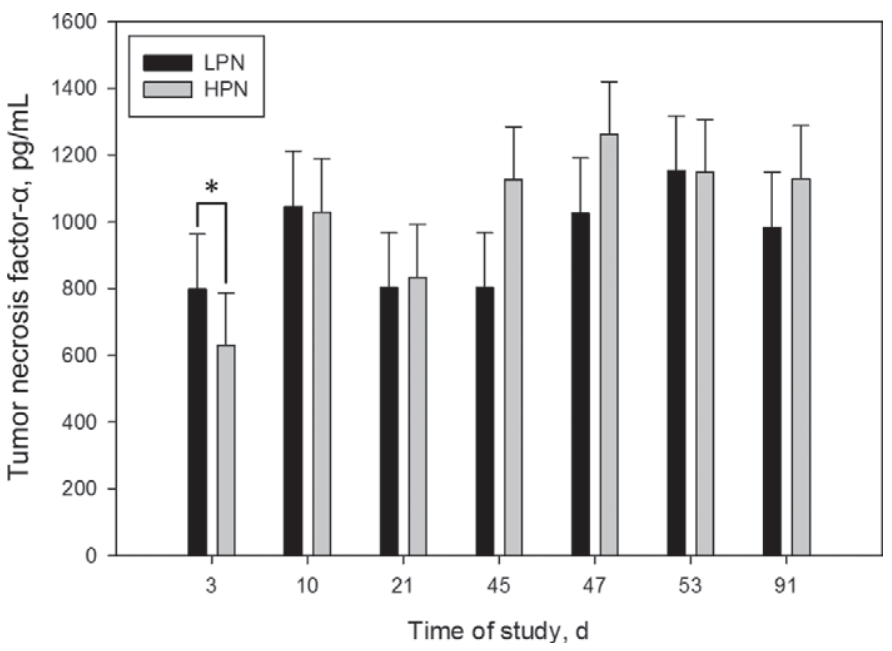

Figure 2. Effects of plane of nutrition on supernatant tumor necrosis factor- $\alpha$ (TNF- $\alpha$ ) on d 3, 10, 21 (neonatal period), 45, 47, 53 (weaning period), and 91 (immediately postweaning). Nutrition $\times$ time: $P=0.12$; sliced effects: ${ }^{*} P<0.05$. Error bars represent SEM (experiment 1$) . \mathrm{LPN}=$ low plane of nutrition; HPN $=$ high plane of nutrition.

evaluate the effect of plane of nutrition on performance and leukocyte responses in dairy calves.

Greater MR intake and lower calf starter consumption in calves fed the HPN diet are consistent with previous data (Cowles et al., 2006; Terré et al., 2006; Hill et al., 2008; Ballou et al., 2013). These results indicate that increasing the consumption of milk or MR reduces the amount of starter consumed by calves during the

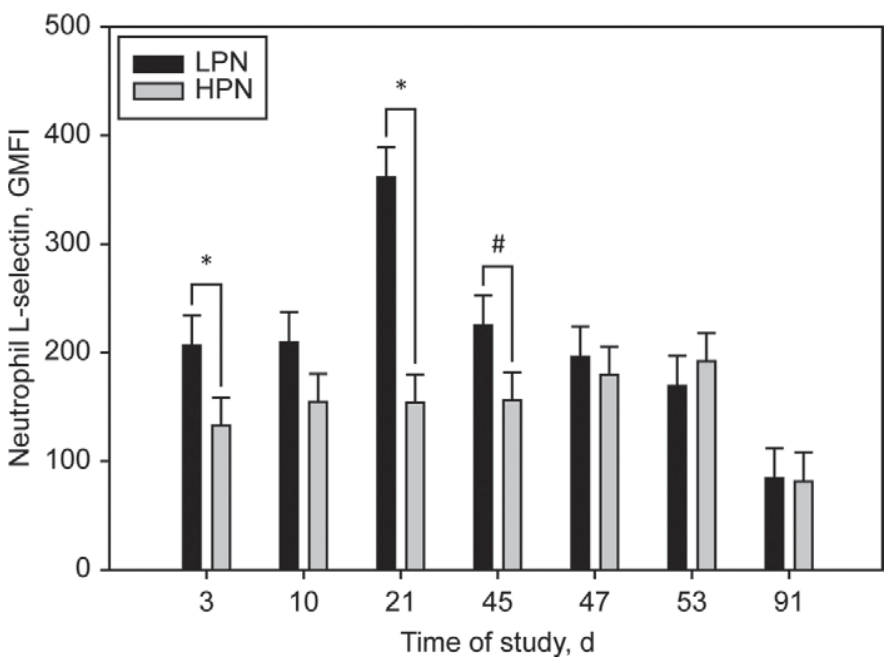

Figure 3. Effects of plane of nutrition on neutrophil L-selectin geometric mean florescence intensity (GMFI) on d 3, 10, 21 (neonatal period), 45, 47, 53 (weaning period), and 91 (immediately postweaning). Nutrition $\times$ time: $P<0.05$; sliced effects: ${ }^{*} P<0.05$, \#P $<0.10$. Error bars represent SEM (experiment 1). LPN = low plane of nutrition; HPN = high plane of nutrition. 
a)

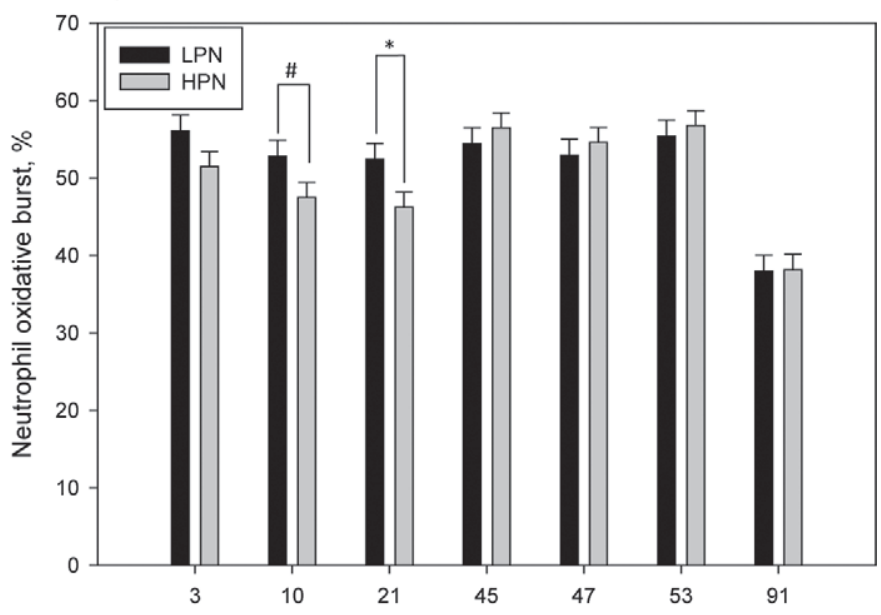

b)

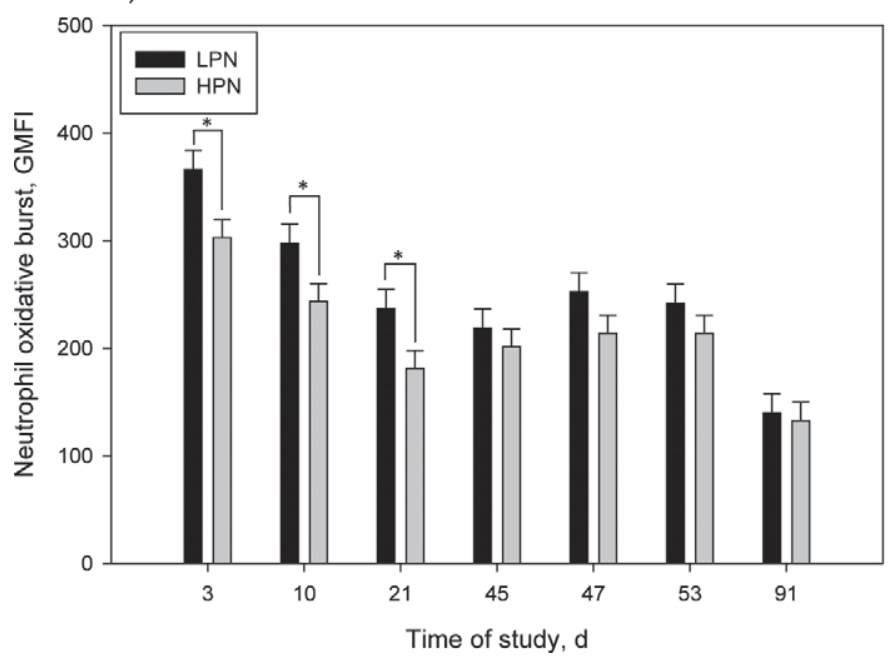

Figure 4. (a) Effects of plane of nutrition on percent of neutrophil oxidative burst on d 3, 10, 21 (neonatal period), 45, 47, 53 (weaning period), and 91 (immediately postweaning). Nutrition $\times$ time: $P<$ 0.05 ; sliced effects: ${ }^{*} P<0.05$, \#P<0.10. Error bars represent SEM (experiment 1). (b) Effects of plane of nutrition on neutrophil oxidative burst geometric mean florescence intensity (GMFI) on d 3, 10, 21 (neonatal period), 45, 47, 53 (weaning period), and 91 (immediately postweaning). Nutrition $\times$ time: $P=0.46$; sliced effects: ${ }^{*} P<0.05$. Error bars represent SEM (experiment 1). LPN = low plane of nutrition; HPN = high plane of nutrition.

preweaning period (Jasper and Weary, 2002; Quigley et al., 2006; Khan et al., 2007). The improvement in ADG and feed:gain ratio in HPN calves relative to LPN calves during the neonatal, preweaning, and overall periods was due to greater $\mathrm{CP}$ and ME intake per kilogram of $\mathrm{BW}^{0.75}$. In summary, feeding a high plane of nutrition to dairy calves improved the overall performance during the preweaning period and had no carryover effect on performance during the immediate postweaning period. Overall ADG was greater in calves fed the HPN diet compared with calves fed the LPN diet during the grower phase in experiment 2. Total DMI did not differ between treatments, but the HPN calves had increased $\mathrm{CP}$ and ME intakes because they were consuming more of the concentrate pellet as designed in the experiment; however, $\mathrm{CP}$ and $\mathrm{ME}$ intake per kilogram of $\mathrm{BW}$ gain was not affected by the plane of nutrition during the grower phase.

All calves were healthy, with no clinical symptoms of systemic disease or mortality throughout both experiments. Further, no differences existed in fecal scores between planes of nutrition during the neonatal period. Plasma urea nitrogen was higher in HPN calves on $d$ 3 , but no differences were observed throughout the rest of the experiment. The difference in plasma urea nitrogen may be related to the greater amount of protein consumed by the HPN calves, indicating that the HPN calves did not use the additional dietary protein for protein synthesis during the first week of life as they adapted to the ex utero environment. In the current study, plasma glucose concentration was greater in HPN calves during the entire preweaning period, which is consistent with previous data (Terré et al., 2006; Daniels et al., 2008; Hanson, 2012).

Tumor necrosis factor- $\alpha$ is a proinflammatory cytokine that is produced by macrophages, among other cells, and initiates the early phases of an acute-phase response, aiding in migration of leukocytes from the periphery to sites of infection. In the current study, LPS-induced secretion of TNF- $\alpha$ was not affected by plane of nutrition except on d 3. An explanation for the elevated TNF- $\alpha$ on d 3 among HPN calves is not clear; in fact, another recent study from our laboratory indicated that Jersey calves fed an LPN diet had elevated TNF- $\alpha$ in whole-blood cultures on $\mathrm{d} 3$, but were not different from the Jersey calves fed the HPN diet during the remaining preweaning period (Hanson, 2012). Quigley et al. (2006) found that feeding MR at various levels did not influence the secretion of TNF- $\alpha$ in calves, which is consistent with Ballou (2012), who reported that the level of nutrition likely has no effect on the inflammatory response of young dairy calves. In the current study, plasma haptoglobin concentration was similar across the diets, indicating that calves in both treatments did not have a lot of systemic inflammation during the study, which is consistent with the lack of symptoms of systemic disease and fecal scores observed among these calves throughout the study.

Results of neutrophil surface L-selectin protein expression, percentage of neutrophils positive for OB, and the OB intensity (GMFI) of neutrophils in experiment 1 showed that many neutrophil responses of LPN calves were greater during the neonatal period. Consistent with our results, Hanson (2012) reported greater neutrophil surface L-selectin protein expression among 
Table 4. Influence of plane of nutrition on nutrient intake and ADG of Holstein calves during the grower period (experiment 2)

\begin{tabular}{|c|c|c|c|c|c|c|}
\hline Item & \multicolumn{2}{|c|}{ Nutrition $^{1}$} & SEM & \multicolumn{3}{|c|}{$P$-value } \\
\hline DMI, kg/d & 4.70 & 4.87 & 0.084 & 0.19 & $<0.05$ & 0.99 \\
\hline $\mathrm{CP}$ intake $/ \mathrm{kg}$ of BW gain, $\mathrm{kg}$ & 0.99 & 1.02 & 0.050 & 0.61 & $<0.05$ & 0.16 \\
\hline $\mathrm{CP}$ intake $/ \mathrm{kg}$ of $\mathrm{BW}^{0.75}, \mathrm{~g}$ & 20.9 & 23.3 & 0.22 & $<0.05$ & $<0.05$ & 0.07 \\
\hline ME intake, Mcal/d & 10.32 & 12.20 & 0.170 & $<0.05$ & $<0.05$ & 0.94 \\
\hline
\end{tabular}

${ }^{1} \mathrm{LPN}=$ low plane of nutrition $(\mathrm{n}=5$ pens, with 5 calves per pen); HPN $=$ high plane of nutrition $(\mathrm{n}=5$ pens, with 5 calves per pen).

Jersey calves fed LPN than those fed a HPN during the preweaning period. However, Ballou (2012) reported no differences due to plane of nutrition on neutrophil $\mathrm{OB}$ at $4 \mathrm{~d}$ of age and that both Jersey and Holstein calves fed an HPN had greater neutrophil OB at $42 \mathrm{~d}$ of age. Perkins et al. (2001) reported no difference in neutrophil L-selectin expression between yearling Holstein steers fed either 210 or $60 \% \mathrm{NE}_{\mathrm{M}}$ (Perkins et al., 2001). A likely explanation for the discrepancy among results in the literature is that many factors are at play and the interaction of those elements determines the response. Some of the potential factors include differences in microbial exposure, the gastrointestinal microbiome, or the intake of specific macro- or micronutrients.

Microbial exposure or differences in the gastrointestinal microbiome could influence measures of neutrophil activity. The innate and adaptive branches of the immune system are not mutually exclusive, so more microbial-induced activation of neutrophil responses may improve the adaptive immunity and the subsequent health of calves. The data from Pollock et al. (1994) and Nonnecke et al. (2003) both report that calves fed LPN had greater measures of adaptive immunity (mitogen-stimulated IFN- $\gamma$ and antigen-specific $\operatorname{IgA}$ and $\operatorname{Ig} \mathrm{G}_{2}$ ), which may be due to differences in microbial exposure or the microbiome. This is largely speculative, but it is important to note that an evaluation of microbial exposure, the microbiome, and adaptive immunity should be included in future research on the role that plane of nutrition plays in leukocyte responses and health of calves.

Another plausible explanation for the observed differences in the innate immune responses may be due to the level of nutrient intake. In the current study, ME and $\mathrm{CP}$ intakes per kilogram of $\mathrm{BW}^{0.75}$ were greater for HPN calves during the preweaning period, which was the same period that immune responses differed the most between LPN and HPN calves. Wing and Barczynski (1984) observed a greater increase in peripheral blood monocytes $3 \mathrm{~d}$ after exposing starved mice to Listeria monocytogenes compared with fed mice. Similarly, neutrophil phagocytosis was enhanced in dry cows fed at maintenance compared with dry cows fed a higherenergy diet (1.34 vs. $1.62 \mathrm{Mcal} / \mathrm{kg}$ of DM; Graugnard et al., 2012). Stapleton et al. (2001) also observed that peritoneal macrophages were stimulated when mice were on a calorie-restricted regimen compared with an ad libitum diet.

Regardless of the mechanism, the current data do not support the hypothesis that calves fed an HPN during the preweaning period will have greater neutrophil activity; in fact, the present data suggest that the opposite is true. More research is needed regarding how plane of nutrition during the preweaning period

Table 5. Influence of plane of nutrition on blood profiles of Holstein calves during the grower period (experiment 2)

\begin{tabular}{|c|c|c|c|c|c|c|}
\hline \multirow[b]{2}{*}{ Item $^{1}$} & \multicolumn{2}{|c|}{ Nutrition $^{2}$} & \multirow[b]{2}{*}{ SEM } & \multicolumn{3}{|c|}{$P$-value } \\
\hline & $\mathrm{LPN}$ & $\mathrm{HPN}$ & & Nutrition & Time & Nutrition $\times$ time \\
\hline Urea nitrogen, mg/dL & 14.4 & 15.7 & 0.76 & 0.24 & 0.01 & 0.27 \\
\hline Glucose, $\mathrm{mg} / \mathrm{dL}$ & 75.9 & 75.7 & 1.97 & 0.94 & 0.06 & 0.32 \\
\hline TNF- $\alpha, p g / m L$ & 819 & 847 & 83.7 & 0.82 & 0.11 & 0.14 \\
\hline L-Selectin, GMFI & 89.4 & 82.3 & 9.51 & 0.62 & 0.64 & 0.95 \\
\hline Neutrophil OB, \% & 46.3 & 43.6 & 2.64 & 0.51 & 0.17 & 0.22 \\
\hline Neutrophil OB, GMFI & 133 & 128 & 11.5 & 0.80 & 0.91 & 0.17 \\
\hline Haptoglobin, OD & 1.3 & 1.6 & 0.20 & 0.33 & 0.61 & 0.55 \\
\hline
\end{tabular}

${ }^{1}$ TNF- $\alpha=$ tumor necrosis factor- $\alpha$; GMFI = geometric mean florescence intensity; OB = oxidative burst; OD = optical density.

${ }^{2} \mathrm{LPN}=$ low plane of nutrition $(\mathrm{n}=5$ pens, with 5 calves per pen); HPN $=$ high plane of nutrition $(\mathrm{n}=5$ pens, with 5 calves per pen). 
influences leukocyte responses. Furthermore, the health implications of altered leukocyte responses to both spontaneous disease and appropriate disease challenge models are needed.

Weaning of both dairy and beef calves was reported to be stressful, as evident by decreased surface neutrophil L-selectin protein and elevated the neutrophil-tolymphocyte ratios in circulation (Lynch et al., 2010; Hulbert et al., 2011). Weaning is potentially stressful because it can be a dramatic change for calves; whether this is more psychological or directly associated with the change in nutrients is unknown. Calves fed an HPN during the preweaning period, if not weaned properly, can have a lag in their postweaning performance (Hill et al., 2012). This suggests that weaning may be more stressful among HPN calves because the change in nutrition is greater. However, the data from the present study do not support that hypothesis and, furthermore, the data do not support the hypothesis that gradually weaning calves is stressful, as evident by the lack of suppressed neutrophil responses during weaning. In support, Hill et al. (2012) reported that gradual weaning of calves that had been fed an HPN did not result in reduced calf starter intake or performance during the immediate postweaning period.

During the immediate postweaning and grower-phase periods, no differences were observed in neutrophil surface L-selectin protein expression, percentage of neutrophil positive for OB, and GMFI of OB-positive neutrophils among the 2 groups. The lack of a plane of nutrition effect during the grower phase was despite the HPN calves consuming more CP and ME. An explanation for the lack of an effect of plane of nutrition during the grower phase on neutrophil responses is not completely clear, but may be due to the age, physiological state, and composition of the diets. Furthermore, the differences in the intakes of $\mathrm{CP}$ and ME per kilogram of metabolic BW between the LPN and HPN groups was not as great as was observed during the neonatal and preweaning periods. In agreement with the current data, Schwertner et al. (2011) observed that OB and OB intensity of positive neutrophils did not differ when growing crossbred steers were fed diets contained either 70 or $30 \%$ concentrate ad libitum or a restricted $70 \%$ concentrate. In the current study, plane of nutrition also did not influence the secretion of TNF- $\alpha$ when wholeblood cultures were stimulated with LPS. In contrast, Schwertner et al. (2011) reported that the steers fed the $70 \%$ concentrate diet ad libitum secreted more TNF- $\alpha$ and had a greater acute-phase response following an intranasal infectious bovine rhinotracheitis virus challenge compared with the steers fed a $30 \%$ concentrate diet ad libitum. The data from the present study do not support the hypothesis that feeding an HPN during the grower phase will increase the inflammatory response and have greater concentrations of haptoglobin.

In addition to the potential macronutrient effects of the planes of nutrition fed in both experiments, differences in the micronutrient source, micronutrient composition, or other feed additives between the planes of nutrition could have played a role in modulating leukocyte responses or health. The HPN in both experiments could have increased tissue concentrations of many of the microminerals because they consumed greater concentrations of organic trace minerals. A lot of research suggests that many microminerals influence leukocyte responses and performance (Spears, 2003). In addition, the HPN MR, calf starter, and concentrate pellets fed during the grower phase contained additional feed additives not found in the LPN MR or calf starter. Yeast extracts have also been shown to modulate leukocyte responses (Eicher et al., 2010). Future research evaluating the influence of varying planes of nutrition of calves during the preweaning or grower phases should control for micronutrients and feed additives. However, the present data suggest that increased organic micromineral sources, micromineral composition of the complete diet, or feed additives did not increase leukocyte responses of clinically healthy group of calves because during the preweaning period, calves fed the LPN had elevated neutrophil responses and no differences were observed postweaning.

\section{CONCLUSIONS}

Under the conditions of the current study, Holstein calves fed an HPN had greater ADG and were more efficient than calves fed an LPN. Neutrophil responses were greater in calves fed an LPN compared with calves fed an HPN during the preweaning period; however, this effect was not observed during the immediate postweaning or grower periods. The exact mechanism(s) underlying the more active neutrophil responses of the LPN during the preweaning period are not known, and more research is needed to elucidate the mechanism(s) and the health implications of the more active neutrophil responses.

\section{ACKNOWLEDGMENTS}

The authors thank Logan Jackson and Devin Hanson with Texas Tech University (Lubbock) and Jeff Dailey with the US Department of Agriculture-Agricultural Research Service (Lubbock, TX) for their assistance with animal husbandry. The authors also acknowledge the milk replacer donations and feeding recommendations made by Land O'Lakes Animal Milk Products Co. (Shoreview, MN). B. S. Obeidat thanks Jordan 
University of Science and Technology (Irbid, Jordan) for financial support during his sabbatical leave at Texas Tech University.

\section{REFERENCES}

AOAC International. 1995. Official Methods of Analysis. 16th ed. AOAC International, Arlington, VA.

Ballou, M. A. 2012. Immune responses of Holstein and Jersey calves during the pre- and immediate postweaned periods when fed varying planes of milk replacer. J. Dairy Sci. 95:7319-7330.

Ballou, M. A., C. J. Cobb, T. J. Earleywine, and B. S. Obeidat. 2013 Interaction of breed and plane of milk replacer nutrition on the performance of pre- and postweaned dairy calves. Prof. Anim. Sci. 29:116-123.

Ballou, M. A., R. C. Gomes, and E. J. DePeters. 2009. Supplemental fish oil does not alter immune competence or the pathophysiological response to an intramammary infusion of endotoxin in peripartum multiparous Holstein cows. J. Dairy Res. 76:165-172.

Blome, R. M., J. K. Drackley, F. K. McKeith, M. F. Hutjens, and G. C. McCoy. 2003. Growth, nutrient utilization, and body composition of dairy calves fed milk replacers containing different amounts of protein. J. Anim. Sci. 81:1641-1655.

Brown, E. G., M. J. VandeHaar, K. M. Daniels, J. S. Liesman, L. T. Chapin, J. W. Forrest, R. M. Akers, R. E. Pearson, and M. S. Weber Nielsen. 2005. Effect of increasing energy and protein intake on mammary development in heifer calves. J. Dairy Sci. 88:595-603.

Cowles, K. E., R. A. White, N. L. Whitehouse, and P. S. Erickson. 2006. Growth characteristics of calves fed an intensified milk replacer regimen with additional lactoferrin. J. Dairy Sci. 89:48354845.

Daniels, K. M., S. R. Hill, K. F. Knowlton, R. E. James, M. L. McGilliard, and R. M. Akers. 2008. Effects of milk replacer composition on selected blood metabolites and hormones in preweaned heifers. J. Dairy Sci. 91:2628-2640.

Eicher, S. D., I. V. Wesley, V. K. Sharma, and T. R. Johnson. 2010. Yeast cell-wall products containing $\beta$-glucan plus ascorbic acid affect neonatal Bos taurus calf leukocyte and growth after a transport stressor. J. Anim. Sci. 88:1195-1203.

Foote, M. R., B. J. Nonnecke, D. C. Beitz, and W. R. Waters. 2007. High growth rate fails to enhance adaptive immune responses of neonatal calves and is associated with reduced lymphocyte viability. J. Dairy Sci. 90:404-417.

Graugnard, D. E., M. Bionaz, E. Trevisi, K. M. Moyes, J. L. SalakJohnson, R. L. Wallace, J. K. Drackley, G. Bertoni, and J. J. Loor. 2012. Blood immunometabolic indices and polymorphonuclear neutrophil function in peripartum dairy cows are altered by level of dietary energy prepartum. J. Dairy Sci. 95:1749-1758.

Hanson, D. 2012. The influence of milk replacer plane of nutrition on the performance, innate immune responses and pathophysiological response to a sub-clinical Salmonella typhimurium challenge. MS Thesis. Texas Tech University, Lubbock.

Hill, S. R., K. F. Knowlton, K. M. Daniels, R. E. James, R. E. Pearson, A. V. Capuco, and R. M. Akers. 2008. Effects of milk replacer composition on growth, body composition, and nutrient excretion in preweaned Holstein heifers. J. Dairy Sci. 91:3145-3155.

Hill, T. M., H. G. Bateman II, J. M. Aldrich, and R. L. Schlotterbeck. 2012. Methods of reducing milk replacer to prepare dairy calves for weaning when large amounts of milk replacer have been fed. Prof. Anim. Sci. 28:332-337.

Hulbert, L. E., and M. A. Ballou. 2012. Innate immune responses and health of individually reared Holstein calves after placement into transition-pens $23 \mathrm{~d}$ after weaning. J. Dairy Res. 79:333-340.

Hulbert, L. E., C. J. Cobb, J. A. Carroll, and M. A. Ballou. 2011. Effects of changing milk replacer feedings from twice to once daily on Holstein calf innate immune responses before and after weaning. J. Dairy Sci. 94:2557-2565.
Jasper, J., and D. M. Weary. 2002. Effects of ad libitum intake on dairy calves. J. Dairy Sci. 85:3054-3058.

Khan, M. A., H. J. Lee, W. S. Kim, S. B. Kim, K. S. Ki, J. K. Ha, H. G. Lee, and Y. J. Choi. 2007. Pre- and postweaning performance of Holstein female calves fed milk through step-down and conventional methods. J. Dairy Sci. 90:876-885.

Larson, L. L., F. G. Owen, J. L. Albright, R. D. Appleman, R. C. Lamb, and L. D. Muller. 1977. Guidelines toward more uniformity in measuring and reporting calf experimental data. J. Dairy Sci. 60:989-991.

Lofgreen, G. P., J. R. Dunbar, D. G. Addis, and J. G. Clark. 1975. Energy level in starting rations for calves subjected to marketing and shipping stress. J. Anim. Sci. 41:1256-1265.

Lynch, E. M., B. Earley, M. McGee, and S. Doyle. 2010. Effect of abrupt weaning at housing on leukocyte distribution, functional activity of neutrophils, and acute phase protein response of beef calves. BMC Vet. Res. 6:39-47.

NAHMS (National Animal Health Monitoring System). 2007. Heifer calf health and management practices in the United States. United States Department of Agriculture Animal and Plant Health Inspection Service: Veterinary Services (USDA:APHIS:VS), Ft. Collins, CO.

Nonnecke, B. J., M. R. Foote, J. M. Smith, B. A. Pesch, and M. E. Van Amburgh. 2003. Composition and functional capacity of blood mononuclear leukocyte populations from neonatal calves on standard and intensified milk replacer diets. J. Dairy Sci. 86:3592-3604

NRC. 2001. Nutrient Requirements of Dairy Cattle. 7th rev. ed. National Academies Press, Washington, DC

Perkins, K. H., M. J. VandeHaar, R. J. Tempelman, and J. L. Burton. 2001. Negative energy balance does not decrease expression of leukocyte adhesion or antigen-presenting molecules in cattle. J. Dairy Sci. 84:421-428.

Pollock, J. M., T. G. Rowan, J. B. Dixon, and S. D. Carter. 1994 Level of nutrition and age at weaning: Effects on humoral immunity in young calves. Br. J. Nutr. 71:239-248.

Quigley, J. D., T. A. Wolfe, and T. H. Elsasser. 2006. Effects of additional milk feeding on calf health, growth, and selected blood metabolites in calves. J. Dairy Sci. 89:207-216.

Rivera, J. D., M. L. Galyean, and W. T. Nichols. 2005. Review: Dietary roughage concentration and health of newly received cattle. Prof. Anim. Sci. 21:345-351.

Schwertner, L. R., M. L. Galyean, L. E. Hulbert, J. A. Carroll, and M. A. Ballou. 2011. Effects of dietary source and intake of energy on immune competence and the response to an infectious bovine rhinotracheitis virus (IBRV) challenge in cattle. Livest. Sci. 141:259-266.

Sellers, M. D., L. E. Hulbert, and M. A. Ballou. 2013. Technical note: Determination of preanalysis storage temperature and time allowances for ex vivo innate immune responses. J. Dairy Sci. 96:384389 .

Soberon, F., E. Raffrenato, R. W. Everett, and M. E. Van Amburgh. 2012. Preweaning milk replacer intake and effects on long-term productivity of dairy calves. J. Dairy Sci. 95:783-793.

Spears, J. W. 2003. Trace mineral bioavailability in ruminants. J. Nutr. 133:1506S-1509S.

Stapleton, P. P., J. Fujita, E. M. Murphy, H. A. Naama, and J. M. Daly. 2001. The influence of restricted calorie intake on peritoneal macrophage function. Nutrition 17:41-45.

Terré, M., M. Devant, and A. Bach. 2006. Performance and nitrogen metabolism of calves fed conventionally or following an enhancedgrowth feeding program during the preweaning period. Livest. Sci. 105:109-119.

Wing, E. J., and L. K. Barczynski. 1984. Effect of acute nutritional deprivation on immune function in mice. II. Response to sublethal radiation. Clin. Immunol. Immunopathol. 30:479-487. 